Abstracta Iranica Abstracta Iranica

Revue bibliographique pour le domaine irano-aryen

Volume 32-33 | 2013

Comptes rendus des publications de 2009-2010

\title{
Roham Alvandi. Muhammad Reza Pahlavi and the Bahrain Question, 1968-1970
}

\section{Christophe Werner}

\section{(2) OpenEdition}

1 Journals

Édition électronique

URL : http://journals.openedition.org/abstractairanica/40756

DOI : 10.4000/abstractairanica.40756

ISSN : 1961-960X

\section{Éditeur :}

CNRS (UMR 7528 Mondes iraniens et indiens), Éditions de l'IFRI

\section{Édition imprimée}

Date de publication : 1 décembre 2013

ISSN : 0240-8910

\section{Référence électronique}

Christophe Werner, «Roham Alvandi. Muhammad Reza Pahlavi and the Bahrain Question, 1968-1970 ", Abstracta Iranica [En ligne], Volume 32-33 | 2013, document 285, mis en ligne le 01 juillet 2016,

consulté le 27 septembre 2020. URL : http://journals.openedition.org/abstractairanica/40756 ; DOI : https://doi.org/10.4000/abstractairanica.40756

Ce document a été généré automatiquement le 27 septembre 2020.

Tous droits réservés 


\title{
Roham Alvandi. Muhammad Reza Pahlavi and the Bahrain Question, 1968-1970
}

\author{
Christophe Werner
}

\section{RÉFÉRENCE}

Roham Alvandi. « Muhammad Reza Pahlavi and the Bahrain Question, 1968-1970 ».

British Journal of Middle Eastern Studies, 37, 2010, p. 159-177.

Depuis sa publication en 2010, cet article qui est d'abord une étude excellente et très détaillée sur l'histoire diplomatique et la politique étrangère de l'Iran à l'époque Pahlavi a gagné une actualité inattendue pour deux raisons. Les révoltes du " printemps arabe » se sont également déroulées à Bahreïn dirigeant l'attention vers la majorité chiite dans cet émirat du golfe et son histoire commune avec Iran. De plus, les discussions sur la politique nucléaire de l'Iran et la puissance de l'Iran dans la région du moyen orient et surtout dans le golfe persique s'expliquent mieux si l'on prend en considération le contexte historique.

Bahreïn était sous la suzeraineté de l'empire Safavide depuis 1602 jusqu'à 1783, date à laquelle les al-Khalifah ont pris le contrôle de cette île. Au XIX ${ }^{\mathrm{e}} \mathrm{s}$. Bahreïn fut reconnue comme un état indépendant sous la protection britannique, en dépit des protestations du gouvernement d'Iran après la grande guerre. Avec la retraite imminente des Anglais du golfe Persique dans les années soixante, le chah cherchait à adopter une stratégie lui permettant de renoncer aux prétentions iraniennes sans perdre la face. Dans un processus qui prit quelques années, et avec le soutien des Nations unies et du tribunal international de La Hague, le majlis iranien accepta finalement de reconnaître la souveraineté de Bahreïn en 1970. Un an plus tard, le chah occupait les petites iles d'Abu Musa et de Tunbs. 
3 Alvandi dépeint le chah Mohammad Reza comme un monarque circonspect et prudent qui était capable de manœuvrer d'une manière habile sur la scène internationale.

\section{AUTEURS}

\section{CHRISTOPHE WERNER}

Philipps-Univesität, Marburg 